\title{
Defined Study Agent Transfer
}

National Cancer Institute

\section{Source}

National Cancer Institute. Defined Study Agent Transfer. NCI Thesaurus. Code C93376.

An administrative activity defined at a global library level that is an action in which an authorized party at a designated study site dispenses or receives a study agent to/from a study subject, though as a defined activity, no actual study subject is identified. 